Editorial

\title{
Delivery room resuscitation of the newborn; a continuous dilemma
}

Volume I Issue 5 - 2014

\section{Editorial}

Neonatal resuscitation is an attempt to facilitate the dynamic transition from fetal to neonatal physiology. Advances in the current practices in delivery room management of the neonate are continuous especially in cardiopulmonary resuscitation techniques for term and preterm infants and in the areas of cerebral resuscitation and thermoregulation as well as resuscitation in special circumstances (such as the presence of congenital anomalies). However, many controversies existed and future trends in neonatal resuscitation need to be more explored.

The 2010 International Consensus on Cardiopulmonary Resuscitation addresses many new concepts and changes in neonatal resuscitation program including assessment of cardiorespiratory transition and need for resuscitation, oxygen use in neonatal resuscitation, meconium suctioning at perineum, ventilation strategies, use of continuous positive airway pressure, devices for assisting ventilation, use of exhaled $\mathrm{CO} 2$ detectors to confirm tracheal tube placement, chest compressions, medications, vascular access, temperature control and timing of cord clamping. ${ }^{2}$

Of these advances, ventilation strategies during resuscitation and use of positive pressure ventilation have remained the mainstay of treatment for respiratory distress in newborns especially in preterm babies in order to prevent ventilatory induced lung injury and subsequent development of complications as broncho-pulmonary dysplasia (BPD) - which is based on lung inflammation. ${ }^{3}$

Many clinical trials in these domains are running especially use of sustained lung versus bag and mask inflation (SLOMI TRIAL) in delivery room resuscitation to reduce the need for intubation and mechanical ventilation, and improve respiratory outcome in preterm neonates. ${ }^{4}$

The Journal of Pediatrics\& Neonatal Care welcomes, helps and supports all health care providers to exchange ideas and opinions that strive for more efficient care and improvement in delivery room resuscitation especially in developing countries and prevent subsequent complications of such procedures.
M. Sami El-Shimi

Department of Pediatrics, Ain Shams University, Egypt

Correspondence: Sami El Shimi, Professor of Pediatrics, Department of Pediatrics, Ain Shams University, Egypt, Tel 00201223169966,Email samichimi53@hotmail.com

Received: August 08, 2014 | Published: September 18, 2014

\section{Acknowledgments}

None.

\section{Conflicts of Interest}

There is no conflict of interest.

\section{Funding}

None.

\section{References}

1. Rajani AK, Chitkara R, Halamek LP. Delivery room management of the newborn. Pediatr Clin North Am. 2009;56(3):515-535.

2. Perlman JM, Willie J, Kattwinkel J, et al. Part 11: Neonatal resuscitation: 2010 International Consensus on Cardiopulmonary Resuscitation and Emergency Cardiovascular Care Science with Treatment Recommendations. Circulation. 2010;122(16 Suppl 2):S516-S538.

3. The American Academy of Pediatrics. Respiratory support in preterm infants at birth. Pediatrics. 2014;133(1):171-174.

4. El-Shimi MS, Awad HAS, El-Gammasy TM, et al. Sustained Lung Inflation versus Bag and Mask Ventilation in the delivery room respiratory management of preterm infants. Arch Dis Child (in press). 2014. 